\title{
Correction to: Childhood risk factors for adulthood chronic kidney disease
}

\author{
Michal Stern-Zimmer ${ }^{1,4} \cdot$ Ronit Calderon-Margalit ${ }^{2} \cdot$ Karl Skorecki $^{3} \cdot$ Asaf Vivante $^{1,4}$ \\ Published online: 14 July 2020 \\ (C) IPNA 2020
}

\section{Correction to: Pediatr Nephrol}

https://doi.org/10.1007/s00467-020-04611-6

The authors regret that the name of the author Michal SternZimmer was incorrectly rendered as "Michal Stern Zimmer." The original article has been corrected.

Publisher's note Springer Nature remains neutral with regard to jurisdictional claims in published maps and institutional affiliations.

The online version of the original article can be found at https://doi.org/ 10.1007/s00467-020-04611-6

Asaf Vivante

asafvivante@gmail.com

1 Pediatric Department B and Pediatric Nephrology Unit, Edmond and Lily Safra Children's Hospital, Sheba Medical Center,

Tel Hashomer 5262000, Ramat Gan, Israel

2 Braun School of Public Health, Hadassah-Hebrew University, Jerusalem, Israel

3 Azrieli Faculty of Medicine, Bar-Ilan University, Safed, Israel

4 Sackler Faculty of Medicine, Tel - Aviv University, Tel Aviv, Israel 